\title{
The 42-kDa coat protein of Andean potato mottle virus acts as a transcriptional activator in yeast
}

M.S. Vidal ${ }^{1}$ and R. Margis ${ }^{1,2}$

\section{Correspondence}

R. Margis

Laboratório de Genética Molecular

Vegetal

Departamento de Genética

Instituto de Biologia, CCS, UFRJ

21944-970 Rio de Janeiro, RJ

Brasil

Fax: +55-21-2590-0111

E-mail: margisr@ufrj.br

Received August 7, 2001

Accepted January 22, 2002

\author{
'Laboratório de Genética M olecular Vegetal, Departamento de Genética, \\ Instituto de Biologia, Universidade Federal do Rio de Janeiro, Rio de Janeiro, RJ, Brasil \\ ${ }^{2}$ Departamento de Bioquímica, Instituto de Química, \\ Universidade Federal do Rio de Janeiro, Rio de Janeiro, RJ, Brasil
}

\section{Abstract}

Interactions of viral proteins play an important role in the virus life cycle, especially in capsid assembly. Andean potato mottle comovirus (APMoV) is a plant RNA virus with a virion formed by two coat proteins ( $\mathrm{CP} 42$ and $\mathrm{CP} 22)$. Both APMoV coat protein open reading frames were cloned into pGBT9 and pGAD10, two-hybrid system vectors. HF7c yeast cells transformed with the p9CP42 construct grew on yeast dropout selection media lacking tryptophan and histidine. Clones also exhibited B-galactosidase activity in both qualitative and quantitative assays. These results suggest that $\mathrm{CP} 42$ protein contains an amino acid motif able to activate transcription of His3 and lacZ reporter genes in Saccharomyces cerevisiae. Several deletions of the $\mathrm{CP} 42$ gene were cloned into the pGBT9 vector to locate the region involved in this activation. CP42 constructions lacking 12 residues from the C-terminal region and another one with 267 residues deleted from the $\mathrm{N}$-terminus are still able to activate transcription of reporter genes. However, transcription activation was not observed with construction p9CP42 $\triangle \mathrm{C} 57$, which does not contain the last 57 amino acid residues. These results demonstrate that a transcription activation domain is present at the $\mathrm{C}$-terminus of CP42 between residues 267 and 374.

\section{Introduction}

Andean potato mottle virus (APMoV) is a plant virus endemic in South America (1) and a member of the Comovirus genus and Comoviridae family, of which cowpea mosaic virus (CPMV) is the type member (2). APMoV infects economically important Solanaceae plants, such as potato, tomato, eggplant and pepper. The symptoms pro-

\section{Key words}

- Andean potato mottle virus

- Virus assembly

- Coat protein

- Transactivation

- Yeast two-hybrid system duced by APMoV infection include mild to severe mottling, systemic necrotic spots, leaf deformation, and plant stunting (1). The genomic structure of APMoV consists of two plus-stranded RNA molecules, designated as RNA-1 and RNA-2, of $5.6 \mathrm{~kb}$ (3) and 3.5 kb (4), respectively. Viral RNAs are encapsulated separately in icosahedral particles approximately 28-30 nm in diameter. Comoviruses typically have two types of coat pro- 
teins, i.e., the large and the small subunits. Virus particles contain 60 copies each of large and small coat proteins arranged with pseudo $\mathrm{T}=3(\mathrm{P}=3)$ symmetry, the large and small subunits being situated around the three- and five-fold symmetry axes, respectively (5). APMoV genomic RNAs are 3'end polyadenylated and linked to a virusencoded peptide at their 5'-end (Figure 1). These RNAs direct the synthesis and subsequent processing of large precursor polyproteins. APMoV RNA-1 encodes a single polyprotein processed in cis by a proteinase domain that gives origin to proteins related to viral replication such as helicase, virus-encoded peptide, protease and the RNA-dependent RNA polymerase. RNA-2, as a result of additional initiation at a second inframe AUG codon, directs the synthesis of two distinct polyproteins. Both are processed in trans by the RNA-1-encoded proteinase to produce a pair of $\mathrm{N}$-terminal proteins, that allow viral infection to move throughout the plant, and the proteins of the virion (4). The two coat proteins, $\mathrm{CP} 42$ and $\mathrm{CP} 22$, have molecular masses of approximately 42 and $22 \mathrm{kDa}$, respectively (6).

Viruses need to protect their genome from nuclease degradation to establish a successful infection. This is achieved through encapsidation by the viral coat proteins. The assembly of viruses involves protein folding, protein assembly, and nucleic acid recognition. This process occurs via discrete intermediate units sometimes aided by a temporary scaffold. In simple spherical viruses, the relationship between assembly units and three-dimensional structure is best documented for picornaviruses in which the three larger coat proteins have the same fold and are similar to the single chain protein that is present in the capsid of many plant RNA viruses (7). A similar assembly is observed in small, spherical RNA plant viruses, in particular for Southern bean mosaic virus, tomato bushy stunt virus, and turnip crinkle virus (8). A preliminary crystallographic anal- ysis at $3.5-\AA$ resolution has shown that the CPMV structure is very similar to that of animal picornaviruses (9). For bean pod mottle virus, another member of the Comoviridae family, a well-ordered RNA interaction with each asymmetric unit of the coat particle was detected and enabled the construction of a model for RNA packing in the bean pod mottle virus middle component (10).

Viral coat proteins play an important role in the interaction of virus particles with their vector (11). Several studies have been conducted in an effort to investigate heteroencapsidation due to risks for the generation of novel viral pathogens with altered transmission properties (12). The major functions of the coat protein are assumed to be the protection of viral RNAs within the infected cell and to allow transmission of the viral genome from plant to plant, either mechanically or by vectors such as insects, nematodes, or fungi. Studies achieved by exchanging the coat protein gene of the whiteflytransmitted African cassava mosaic virus (ACMV) with that of the leafhopper-transmitted beet curly top virus (BCTV) produced a leafhopper-transmissible ACMVBCTV:coat protein chimera, emphasizing the importance of geminivirus coat protein to dictate which insect vector may transmit the virus (13). Coat protein may be required for cell-to-cell movement of the viral RNA through modified plasmodesmata and also for systemic movement of the virus from leaf to leaf through the vascular system of the plant (14).

The coat proteins can play an important regulatory role in the cycle of viral infection. The coat proteins of members of the Ilarvirus genus and alfalfa mosaic virus have a critical function in the infection process of their genomic RNAs. Synthetic transcripts or purified genomic RNAs become infectious and able to replicate only upon the addition of few coat protein molecules. This phenomenon is known as genome activation and indicates that coat proteins have also a func- 
tional role in viral replication $(15,16)$.

In the present study, we examined the interactions between the two APMoV coat proteins (CP42 and CP22) using a two-hybrid system. The results of transcriptional activation, obtained with the $\mathrm{CP} 42$ construct in the yeast system, will permit further experiments in order to determine a functional map of CP42 transactivation domains.

\section{Material and Methods}

\section{DNA manipulation and plasmid constructions}

Restriction endonucleases and DNA-modifying enzymes were purchased from New England Biolabs Inc. (Beverly, MA, USA), GibcoBRL (Gaithersburg, MD, USA) and Amersham-Pharmacia Biotech (Uppsala, Sweden). Chemicals for yeast culture media and assays were from Difco Laboratories (Detroit, MI, USA), Reagen (Rio de Janeiro, RJ, Brazil) or Sigma (St. Louis, MO, USA). Recombinant DNA manipulations were carried out using standard protocols (17). The APMoV CP42and $\mathrm{CP} 22$-coding regions were cloned into the plasmids pGBT9 and pGAD10 (18) after specific amplification by the polymerase chain reaction (PCR). Oligonucleotide primers were designed to incorporate Bam $\mathrm{HI}$ and Pst $\mathrm{I}$ restriction enzyme sites at the 5'- and 3'-ends of the respective genes. Reactions were performed with $100-\mu 1$ preparations containing $50 \mathrm{ng}$ of template DNA - pM15, which contains the full APMoV RNA-2 open reading frame (4), 125 $\mathrm{nM}$ of each primer pair (as described in Table 1), $0.25 \mathrm{mM}$ of each dATP, dCTP, dGTP and dTTP, $6 \mathrm{mMMgCl}_{2}, 50 \mathrm{mM} \mathrm{KCl}, 10 \mathrm{mM}$ Tris$\mathrm{HCl}, \mathrm{pH} 8.3$, and 2.5 units of Taq DNA polymerase. Different combinations of forward primers: CP22F (ttG GAT CCG CTT TTG TAG TCC ATG TAT AAA TGT TTG G), CP42F (ttG GAT CCT GGA CCT TGC GCA GTT TG), N29 (ttG GAT CCT AGG TAG ATT TTC AAT ACC CAT GAC), N160 (ttG GAT CCT AAC AAC TGA CTG TGC TGT CGC), N267 (ttG GAT CCT AAT GGA TCA
GGA CGT GTC TTA TAG), and N330 (ttG GAT CCT AGT AAA GAT TGC ATA GCT TCT ACC) and reverse primers: CP22R (ttg gat cCT GCA GCT ACT TTA GTA TTG GAA GCA TAC CAG), CP42R (aaG GAT CCT GCA GCT ACT GAG GCC ACG CCA CA), C57 (aag gat cCT GCA GAA CAA CAT ACA AAT AAG GAC AAC), C120 (aag gat cCT GCA GTG CTA TAA AAG CCA AAA GCG), C217 (aag gat cCT GCA GGG GTG TTG CAC TCC ATG G), and C358 (aag gat cCT GCA GAC CTG CTG CAA TTC TGC TAT TC) were used in PCR amplifications (Table 1). Primer nucleotide sequences are from $5^{\prime}$ to $3^{\prime}$, restriction sites used to clone the PCR fragments are given in bold and other non-viral sequences are given in lower case. CP42 PCR products were digested with BamHI, purified from agarose gels and than cloned into Bam HI-digested pGBT9 or BamHI/BglII-digested pGAD10. The PCR product corresponding to the $\mathrm{CP} 22$ gene was cloned into the BamHI/PstI-digested pGBT9 and pGAD10 two-hybrid system vectors. Amino and carboxyl terminal $\mathrm{CP} 42$ deletion mutants were PCR generated using pM15 as template. PCR products corresponding to the six $\mathrm{CP} 42 \mathrm{~N}$-terminal deletions $(\Delta \mathrm{N})$ were cloned into the pGBT9 BamHI site. The six Cterminal deletions $(\Delta \mathrm{C})$ were generated by

Table 1. List of the different APM oV CP22 and CP42 constructs, range of amino acid deletions, primer pairs used and annealing temperature and length of the corresponding PCR-amplified product.

\begin{tabular}{|c|c|c|c|c|}
\hline Plasmid & Deletion & Primer & ${ }^{\circ} \mathrm{C}$ & bp \\
\hline p9CP22 & None & $\mathrm{CP} 22 \mathrm{~F}-\mathrm{CP} 22 \mathrm{R}$ & 68 & 591 \\
\hline p9CP42 & None & CP42F - CP42R & 67 & 1161 \\
\hline p9CP42 2 N29 & $\Delta M^{1} A^{28}$ & $\mathrm{~N} 29-\mathrm{CP} 42 \mathrm{R}$ & 50 & 1034 \\
\hline p9CP42 $4 \mathrm{~N} 160$ & $\Delta M^{1} P^{160}$ & N160 - CP42R & 50 & 681 \\
\hline p9CP42 4 N267 & $\Delta M^{1} A^{266}$ & N267 - CP42R & 50 & 360 \\
\hline p9CP42_N330 & $\Delta \mathrm{M}^{1} \mathrm{~V}^{229}$ & N330 - CP42R & 50 & 171 \\
\hline p9CP42 $\Delta$ N29 $\Delta$ C57 & $\Delta \mathrm{M}^{1} \mathrm{~A}^{28} \Delta \mathrm{V}^{330} \mathrm{Q}^{386}$ & N29 - C57 & 50 & 903 \\
\hline $\mathrm{p} 9 \mathrm{CP} 42 \Delta \mathrm{N} 267 \Delta \mathrm{C} 57$ & $\Delta M^{1} A^{266} \Delta V^{330} Q^{386}$ & N267 - C57 & 50 & 189 \\
\hline p9CР $42 \Delta C 57$ & $\Delta \mathrm{V}^{330} \mathrm{Q}^{386}$ & $\mathrm{CP} 42 \mathrm{~F}-\mathrm{C} 57$ & 50 & 990 \\
\hline p9CP42 $\triangle$ C120 & $\Delta M^{267} Q^{386}$ & $\mathrm{CP} 42 \mathrm{~F}-\mathrm{C} 120$ & 50 & 801 \\
\hline p9CP $42 \Delta C 217$ & $\Delta \mathrm{T}^{161} \mathrm{Q}^{386}$ & $\mathrm{CP} 42 \mathrm{~F}-\mathrm{C} 217$ & 50 & 510 \\
\hline p9СР42 $\triangle$ С358 & $\Delta \mathrm{R}^{30} \mathrm{Q}^{386}$ & $\mathrm{CP} 42 \mathrm{~F}-\mathrm{C} 358$ & 50 & 87 \\
\hline p10CP22 & None & CP22F - CP22R & 68 & 591 \\
\hline p10CP42 & None & CP42F - CP42R & 67 & 1161 \\
\hline
\end{tabular}


cloning the PCR-digested amplification products into the pGBT9 BamHI/PstI site. Construct p9CP42 $\triangle \mathrm{C} 12$ was produced by full amplification of the $\mathrm{CP} 42$ domain with primers $\mathrm{CP} 42 \mathrm{~F}$ and $\mathrm{CP} 42 \mathrm{R}$ followed by BamHI and $P s t \mathrm{I}$ digestion and ligation into the corresponding sites of pGBT9. PstI digestion removes the sequence coding for the 12 residues present at the $\mathrm{C}$-terminus of $\mathrm{CP} 42$. In all these constructions the APMoV CP42 deletion mutants were fused to the C-terminus of the GAL4 DNA-binding domain present in pGBT9.

\section{Yeast transformation}

The yeast strain HF7c [MATa, ura3-52, his3-200, ade2-101, lys2-801, trp1-901, leu23,112, gal4-542, gal80-538, LYS2:: $\mathrm{GAL}_{\mathrm{UAS}}-\mathrm{GAL} 1_{\text {TATA }}$-HIS3 URA3::GAL4 (17-mers) ${ }_{3}$-CYC1 $1_{\text {TATA }}$-lacZ], which contains two reporter genes (His3 and lacZ), was used in all two-hybrid system analyses. Transformation of yeast with the pGBT9 and pGAD10 constructs was performed as previously described (19). Transformed cells were plated onto yeast dropout selection media lacking tryptophan and leucine (SD-W-L) for testing the transformation efficiency, or lacking tryptophan, leucine and histidine (SDW-L-H) for testing and detecting any protein-protein interactions. The positive colonies were obtained from selective plates after 2 days of growth and then submitted to more stringent growth conditions on selective plates containing increasing concentrations of 3-AT (3-amino-1,2,4-triazole). To test the transactivation characteristics of APMoV pGBT9-CP42 constructs, SD without tryptophan was used as the non-selective culture medium and SD lacking tryptophan and histidine was used as the selective medium.

\section{ß-Galactosidase assays}

Two different methodologies were used to evaluate lacZ gene expression in HF7c yeast cells. The first consists of freezing colony filter in liquid nitrogen followed by incubation with X-Gal in Z buffer $\left(60 \mathrm{mM} \mathrm{Na}_{2} \mathrm{HPO}_{4}, 40\right.$ $\mathrm{mM} \mathrm{NaH} \mathrm{PO}_{4}, 10 \mathrm{mM} \mathrm{KCl}, 1 \mathrm{mM} \mathrm{MgSO}$, $\mathrm{pH}$ 7.0, $50 \mathrm{mM}$ B-mercaptoethanol, and 0.3 $\mathrm{mg} / \mathrm{ml} \mathrm{X-Gal)}$ for blue/white screening. The second approach was the liquid culture $\beta$ galactosidase assay, also performed in $\mathrm{Z}$ buffer (20). The $\beta$-galactosidase activity present in a solution of freeze-and-thaw disrupted cells was measured using o-nitrophenyl- $\beta$-Dgalactopyranoside (ONPG) as substrate. One B-galactosidase unit is defined as the amount of enzyme necessary to hydrolyze $1 \mu \mathrm{mol}$ of ONPG to o-nitrophenol and D-galactose per minute (21).

\section{Computer-assisted analysis of protein secondary structure}

The APMoV CP42 GenBank accession number is L16239. The analyses of the secondary and tertiary structure were carried out using the Swiss-Model ProMod package (22) which provides predictions based on the search for homology with sequences of proteins of known structure and integrates the What-If and the What-Check softwares (23).

\section{Results and Discussion}

\section{Analysis of interaction between the APMoV coat proteins}

The introduction of the yeast two-hybrid system in virology has opened new and exciting possibilities for virus assembly studies (24). In the present study, we set out to identify the domains responsible for the possible interactions between the large APMoV CP42 and the small CP22 (Figure 1) using the two-hybrid system (24). Both APMoV coat protein genes were cloned into the pGBT9 and pGAD10 vectors to produce the corresponding $\mathrm{p} 9 \mathrm{CP} 42, \mathrm{p} 9 \mathrm{CP} 22, \mathrm{p} 10 \mathrm{CP} 42$ 
and p10CP22 constructs. Each of these plasmids has the respective wild-type APMoV coat protein fused to the C-terminus of the GAL4 DNA-binding domain in the pGBT9 vector, or to the GAL4 transcription activation domain in pGAD10 (18).

The testing of each construct for selftransactivation of selective or reporter gene transcription is one of the first steps that must be checked in order to use the twohybrid system as a methodology to study the GAL4-based protein-protein interaction. The coat protein constructs p9CP42, p10CP42, p9CP22 and p10CP22 and the control plasmids pGBT9 and pGAD10 were used to transform HF7c yeast cells that were plated

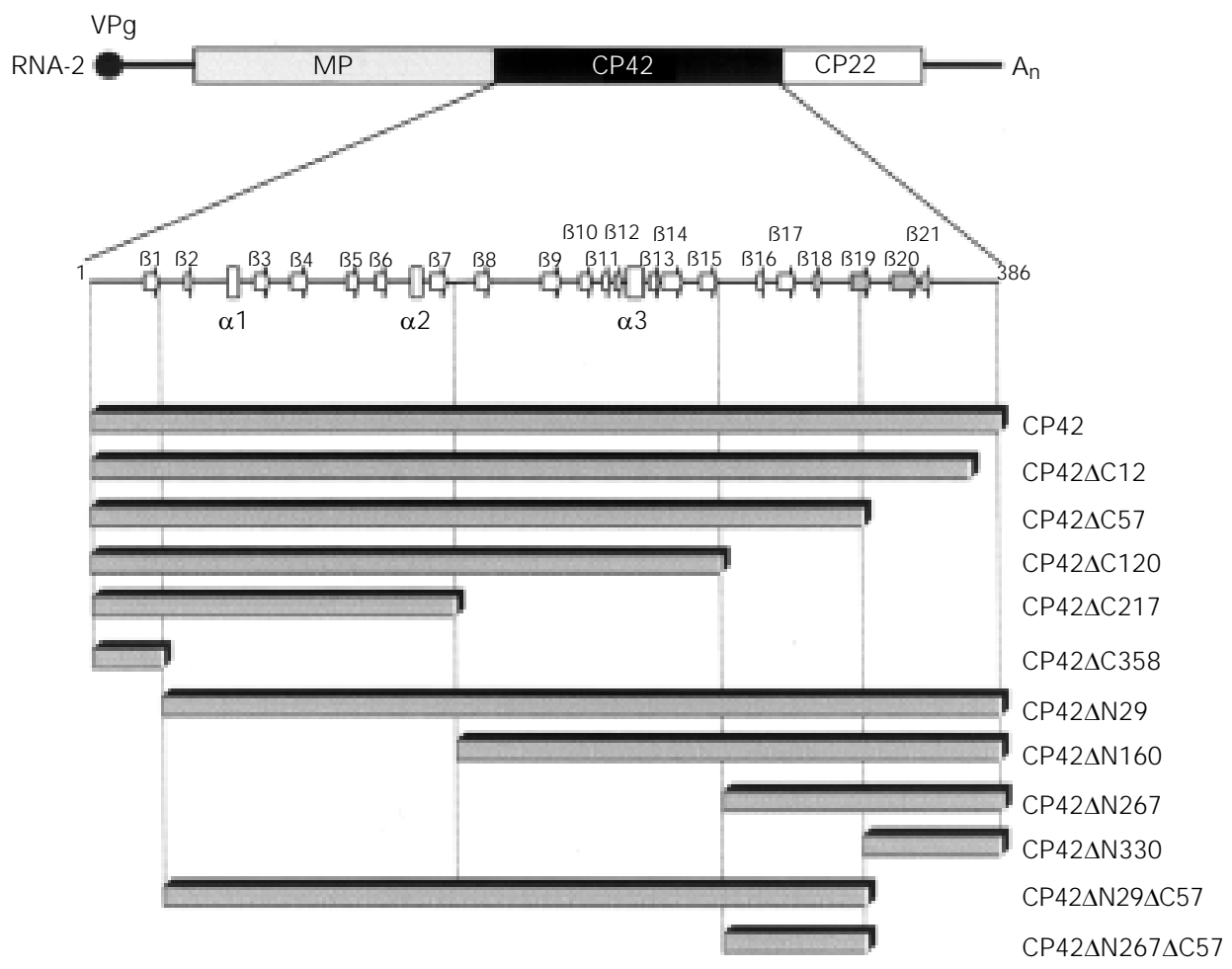

Table 2. Analysis of APM oV CP42 and CP22 yeast transformants and co-transformants growing in different sets of selective media.

\begin{tabular}{|c|c|c|c|c|c|c|c|}
\hline \multirow[t]{2}{*}{ Plasmid } & \multicolumn{6}{|c|}{ SD mediuma } & \multirow[t]{2}{*}{ ß-Galactosidase assay ${ }^{b}$} \\
\hline & $-W$ & $-\mathrm{W}-\mathrm{H}$ & $-\mathrm{L}$ & $-\mathrm{L}-\mathrm{H}$ & $-W-L$ & $-W-L-H$ & \\
\hline pGAD10 & & & $96 ; 152$ & $0 ; 0$ & & & w \\
\hline p10CP42 & & & $200 ; 100$ & $0 ; 0$ & & & w \\
\hline p10CP22 & & & $208 ; 250$ & $0 ; 0$ & & & w \\
\hline pGBT9 & $88 ; 256$ & $0 ; 0$ & & & & & w \\
\hline p9СР42 & $100 ; 300$ & $80 ; 104$ & & & & & $\mathrm{~B}$ \\
\hline p9CP22 & $50 ; 296$ & $0 ; 0$ & & & & & w \\
\hline p9СР22/p10СР42 & & & & & $26 ; 20$ & $0 ; 0$ & w \\
\hline
\end{tabular}

aUpper and lower values of the number of colonies obtained in three independent assays.

bß-Galactosidase activity in qualitative filter assays. " $w$ " corresponds to normal yeast colony color and "B" corresponds to blue colonies with ß-galactosidase activity. 
onto a series of selective media (Table 2). Among these four constructs, plasmid p9CP42 produced a high number of growing colonies when transformed cells were plated onto the selective medium depleted of histidine.

This result indicates that $\mathrm{CP} 42$, when fused to the GAL4-binding domain, was able to activate the transcription of the His 3 and lac Z reporter genes. The same was not observed when the $\mathrm{CP} 42$ protein was fused to the GAL4-activation domain (Table 2). Consequently, it was not possible to test the interaction properties of the two APMoV coat proteins using $\mathrm{p} 9 \mathrm{CP} 42$ and $\mathrm{p} 10 \mathrm{CP} 22$ in double transformation experiments. Thus, the analysis of heterodimer formation by the expression of the $\mathrm{CP} 42$ and $\mathrm{CP} 22$ core proteins in yeast transformed cells was limited to the p9CP22-p10CP42 combination.

In fact, no colony was obtained when the double transformed cells were plated onto the SD-W-L-H media (Table 2), but the efficiency of double transformation was assured by the presence of growing colonies on the SD-W-L selective medium. This result was quite surprising because there are several reports demonstrating that comovirus coat proteins should interact with one another.

Three independent components can be distinguished when members of the Picornaviridae virus family are purified by centrifugation on density gradients, i.e., top, middle, and bottom. The three components have identical protein composition and contain 60 copies of each coat protein. The middle component contains a single molecule of RNA-2 and the bottom component contains a single molecule of RNA-1, but the top component is devoid of RNA (10). The proportion of the top component in wild-type virus preparations is relatively small, suggesting that virus assembly may proceed by mechanisms in which the top component may function as a provirion (25). Another experimental approach revealed that transient expression of the two CPMV coat proteins in protoplasts resulted in the formation of virus-like particles (26). These results showed that the coat proteins were able to stabilize each other, this possibly being the first step in the CPMV assembly process. The same results were obtained when the single capsid protein of arabis mosaic virus was expressed in transgenic plants or in insect cells (27).

The absence of interactions between the two coat proteins has led to the assumption that a constraint should exist in this experimental system. A set of factors may be negatively affecting the interactions of the two APMoV coat protein subunits: the dependence of a third host or viral factor, the differences between the yeast and plant intracellular environment, and especially the secondary and tertiary structures derived from the fusion of the coat proteins at the GAL4 Cterminal domains.

Merits et al. (28) also reported that interactions between potato A virus $\mathrm{P} 1, \mathrm{P} 3$ and other proteins did not give identical results when three methods were used, two of them based on in vitro binding assays and the third being the yeast two-hybrid system. The low expression efficiency or quick turnover of the proteins, the incorrect post-translational modification and unfavorable folding of proteins in the yeast nucleus, or the masking of the DNA-binding or transcriptional activation domain by the fusion proteins are assumptions that cannot be overlooked (28). Finally, detection of protein-protein interactions in the two-hybrid system depends on which protein is fused to which part of the GAL4 transcription factor. Interaction of plant potyvirus RNA polymerase with the viral coat protein was ten times higher when the polymerase was fused to the DNA-binding domain and the coat protein was fused to the activator domain (29).

\section{Transactivation properties of the APMoV major coat protein}

Yeast cells transformed with the p9CP42 
construction were plated onto non-selective media (SD-W) and selective media containing increasing concentrations of 3-AT (SD$\mathrm{W}-\mathrm{H}+3-\mathrm{AT}$ ) in order to confirm the transactivation properties of the APMoV CP42. Yeast cells transformed with the p9CP42 were able to grow on selective media supplemented with 3-AT concentrations as high as $100 \mathrm{mM}$ (Figure 2). These yeast clones were used in B-galactosidase assays and exhibited B-galactosidase activities (Table 2).

Strong evidence supports the involvement of viral coat proteins in replication. In the case of alfalfa mosaic virus, the coat protein is necessary for viral RNA synthesis and initiation of the infection cycle (15). Indeed, the coat protein was found to be tightly associated with the viral RNA polymerase, which was purified by immunoaffinity chromatography with antibodies raised against the coat protein (30). Mutations of basic N-terminal residues of alfalfa mosaic virus coat protein abolished viral replication and its RNA-binding activity (31). The confirmation of reporter gene transactivation by the p9CP42 construct has redirected the original work. Efforts were made to map the functional domains of the APMoV 42-kDa coat protein, since the two-hybrid methodology permits to map functional regions of several other viral proteins $(32,33)$.

\section{Localization of the transcription activation sequence in the APMoV CP42}

In order to identify the $\mathrm{CP} 42$ region able to transactivate the reporter genes, several in-frame CP42 deletions were cloned into the pGBT9 expression vector. Figure 1 shows a schematic representation of the ten $\mathrm{CP} 42$ deletion mutants used in this study. Yeast cells were transformed with pGBT9-based constructs and transformants were plated onto selective (SD-W-H) media. Only two $\mathrm{CP} 42$ derivatives were able to transactivate the transcription of the lac $\mathrm{Z}$ and His 3 genes in yeast cells (Table 3 ): a mutant with a 12- amino acid deletion in the C-terminus (CP42 $\triangle \mathrm{C} 12)$ and a mutant lacking 267 amino acids $(\mathrm{CP} 42 \Delta \mathrm{N} 267)$ at the $\mathrm{N}$-terminus of the CP42 protein (Figures 2 and 3). These results indicate that the transactivator domain resides within the $\mathrm{C}$-terminal region of the CP42 protein between residues 331 and 376 .

Recently, Horváth et al. (32) predicted that some of the functionally important re-

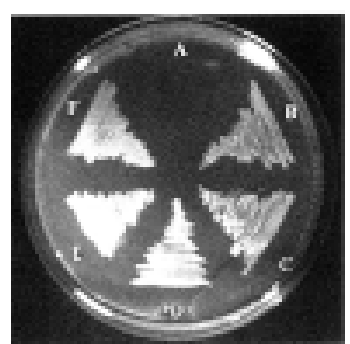

SD-W

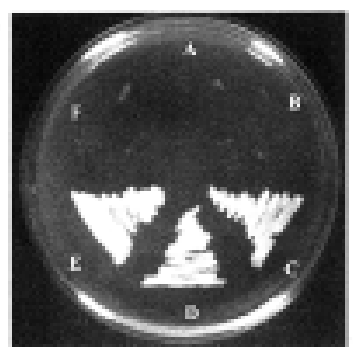

SD-W-H

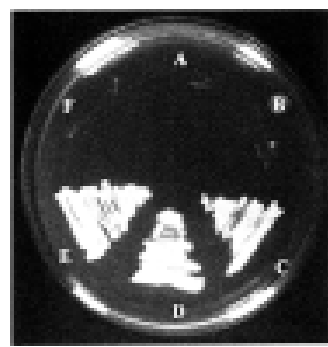

SD-W-H 75 mM 3-AT
Figure 2. Transactivation of the His3 reporter gene by GAL4 DNA-binding domain-CP42 fragment fusion proteins. Transformed HF7c yeast cells were grown on selective medium lacking tryptophan (SD-W), lacking tryptophan and histidine (SD-W-H), and lacking tryptophan and histidine and supplemented with $75 \mathrm{mM}$ 3-amino-1,2,4-triazole (3-AT) (SD-W-H + 75 mM 3-AT). Samples: A) HF7c; B) pGBT9; C) p9CP42; D) p9CP42 _C12; E) p9CP42 $\Delta N 267$ and F) p9CP22.

Table 3. Analysis of the transactivation properties of APM oV CP42 and CP42 deletions.

\begin{tabular}{|c|c|c|c|c|}
\hline \multirow{2}{*}{ Plasmid } & \multicolumn{3}{|c|}{ SD medium ${ }^{a}$} & \multirow{2}{*}{ ß-Galactosidase assay } \\
\hline & $-w$ & $-\mathrm{W}-\mathrm{H}$ & $+3-A T^{b}$ & \\
\hline HF7c & - & - & - & $0.33 \pm 0.03$ \\
\hline pGBT9 & $1768 ; 900$ & $0 ; 0$ & & $0.70 \pm 0.01$ \\
\hline p9CP42 & 1998; 1155 & $105 ; 120$ & ++ & $2.63 \pm 0.20$ \\
\hline p9CP42 2 N29 & $1600 ; 865$ & $0 ; 0$ & & nd \\
\hline p9CP42 $\Delta \mathrm{N} 160$ & $1200 ; 970$ & $0 ; 0$ & & nd \\
\hline p9CP42 2 N267 & $952 ; 918$ & $292 ; 150$ & ++ & $1.98 \pm 0.02$ \\
\hline p9CP42 2 N330 & $895 ; 768$ & $0 ; 0$ & & nd \\
\hline p9СР $42 \Delta \mathrm{C} 12$ & 2000; 997 & 100; 103 & ++ & $1.91 \pm 0.09$ \\
\hline p9CP42 4 C57 & $1568 ; 1200$ & $0 ; 0$ & & nd \\
\hline p9CP42 $\Delta \mathrm{C} 120$ & $1200 ; 1168$ & $0 ; 0$ & & nd \\
\hline p9CP42 $\Delta$ C217 & $1700 ; 1003$ & $0 ; 0$ & & nd \\
\hline p9CP42 $\triangle$ C358 & $998 ; 670$ & $0 ; 0$ & & nd \\
\hline p9CP42 $\Delta$ N29 $\Delta$ C57 & $904 ; 899$ & $0 ; 0$ & & nd \\
\hline $\mathrm{p} 9 \mathrm{CP} 42 \Delta \mathrm{N} 267 \Delta \mathrm{C} 57$ & 1064; 978 & $0 ; 0$ & & nd \\
\hline
\end{tabular}

aUpper and lower values of the number of colonies obtained in three independent assays.

besults obtained by plating transformed yeast onto selective media (SD-W-H) containing 3-AT.

CUnits of ß-galactosidase activity. Values correspond to the means \pm SD of three independent cultures. nd, not determined. 
gions of the maize streak virus RepA and Rep proteins are involved in transcriptional activation and regulation of viral DNA replication by using the two-hybrid system. Hartitz et al. (34) reported the phosphorylation of the geminivirus AL2 protein expressed in

Figure 3. Assay of APM oV CP42 direct transactivation in yeast. CP42 constructs were introduced into HF7c yeast cells as a fusion with the GAL4 DNA-binding domain. Transactivation properties were assayed by the GAL4-mediated activation of the B-Gal activity present in transformed cells. The displacement of yeast transformants on the nitrocellulose filter is: A) pGBT9; B) p9CP42; C) p9CP42 $\triangle \mathrm{C} 12$ and D) $p 9 C P 42 \Delta N 267$.

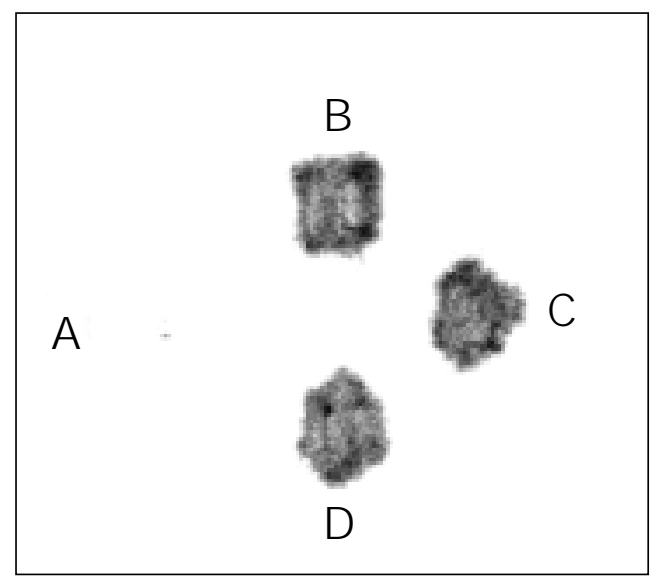

insect cells and that this protein contains a transcriptional activation domain of the acidic type. They also reported that the minimal activation domain comprised the AL2 protein $15 \mathrm{C}$-terminal amino acids.

According to the present results, the occurrence of an activation domain present at the CP42 C-terminal region was postulated. By analyzing the predicted tertiary structure of the wild-type CP42 and those of several deletions of the $\mathrm{CP} 42$ core protein (Figure 4 ), we identified the presence of a loop that may be the interactive region of the protein with the yeast RNA polymerase II. This region is located between amino acid residues 332 and 342 and contains a loop region stabilized by two $\beta$-sheets (Figures 1 and 4). The APMoV CP42 loop contains a glycine and an acidic residue and both are conserved
A

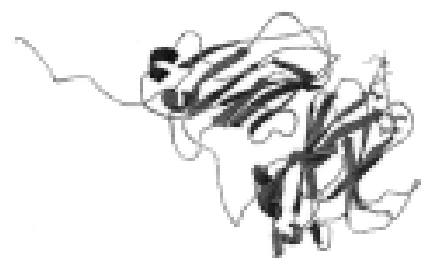

B

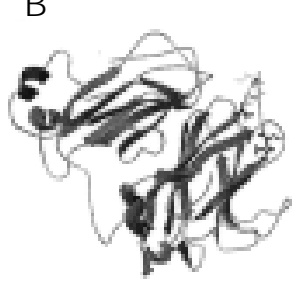

C

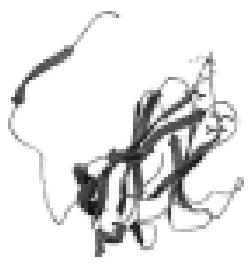

D

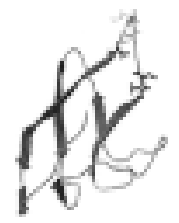

$E$

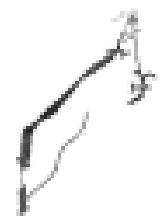

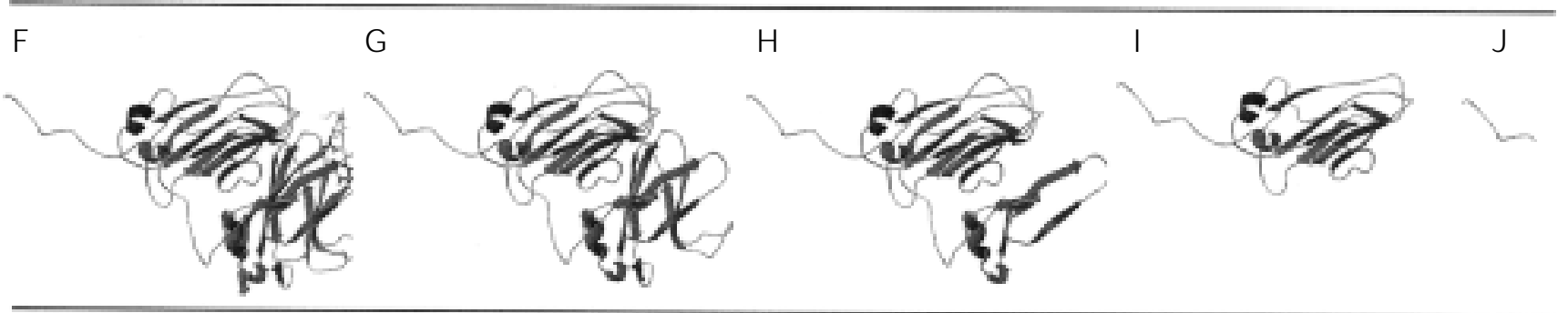

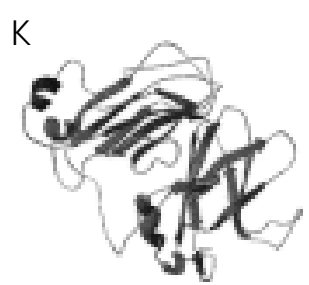

L

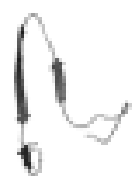

Figure 4. Predicted three-dimensional structure of wild-type and deletion mutants of APMoV CP42. Model A corresponds to the wild-type CP42. Models B to E represent CP42 $\triangle \mathrm{N} 29, \mathrm{CP} 42 \Delta \mathrm{N} 160, \mathrm{CP} 42 \Delta \mathrm{N} 267$ and CP42 $\Delta \mathrm{N} 330$ amino-terminal deletions; $\mathrm{F}$ to J correspond to CP42 $\Delta \mathrm{C} 12, \mathrm{CP} 42 \Delta \mathrm{C} 57$, CP42 $\Delta \mathrm{C} 120, \mathrm{CP} 42 \Delta \mathrm{C} 217$ and CP42 $\triangle \mathrm{C} 358$ carboxy-terminal deletions, and $\mathrm{K}$ and L are the predicted models for the CP42 $4 \mathrm{~N} 29 \Delta \mathrm{C} 57$ and CP42 $\triangle$ N267 $\triangle$ C57 double deletion mutants, respectively. The hypothetical CP42 transactivation loop domain containing one cysteine and two acid amino acid residues is present and identified in models A, B, C, D, E and F. 
in the coat protein sequence of six other comoviruses (alignment not shown). Similar $\beta$-sheet-turn- $\beta$-sheet motifs have been found in other yeast and plant virus transactivators of transcription $(32,35)$. The deletions that abolished the formation of this loop, like CP42 $\Delta$ C57, CP $42 \Delta \mathrm{C} 120, \mathrm{CP} 42 \Delta \mathrm{C} 217, \mathrm{CP}$ $42 \Delta \mathrm{C} 358, \mathrm{CP} 42 \Delta \mathrm{N} 29 \Delta \mathrm{C} 57$ and $\mathrm{CP} 42 \Delta$ $\mathrm{N} 267 \Delta \mathrm{C} 57$, were not able to activate the transcription of the reporter genes (Table 3). When the loop was formed the transcription of the genes analyzed in the two-hybrid system should be expected, but the deletion of 29 amino acids in the N-terminal region of the $\mathrm{CP} 42$ protein $(\mathrm{CP} 42 \Delta \mathrm{N} 29)$ did not activate the reporter genes. According to the predicted structure of this protein, the $\mathrm{N}$ terminal ß-sheet was deleted but the remaining $\mathrm{N}$-terminal unstructured region could spatially block the access to the loop (Figure 4). This may occur with the CP $42 \Delta \mathrm{N} 160$ mutant, that has 160 deleted amino acids in the N-terminal region of the coat protein.

The direct transactivation of reporter genes in yeast cells by plant proteins has been previously described for geminivirus proteins and fits their biological role (32). To better understand the role of this loop in the potential transactivation of transcription, a series of point mutations should be produced in the acidic and glycine conserved residues present on this loop.

\section{References}

1. Fribourg $C E$, J ones $R A C \&$ Koening $R$ (1977). Andean potato mottle, a new member of the cowpea mosaic virus group. Phytopathology, 67: 969-974.

2. Adams MJ , Antoniw J F, Barker $\mathrm{H}$, J ones AT, Murant AF \& Robinson D (1998). Descriptions of Plant Viruses on CD-ROM. Association of Applied Biologists, Wellesbourne, Warwick, UK.

3. Krengiel R, Vicente ACP, Weyne $M$, Shindo N, Brioso PST, Félix DB, Villaroel R, de Oliveira DE \& Timmerman B (1993). Molecular cloning and sequence analysis of a segment from Andean potato mottle virus $B$ RNA encoding the putative RNA polymerase. J ournal of General Virology, 74: 315-318.

4. Shindo N, Vicente ACP, Krengiel R \& de Oliveira DE (1993). Nucleotide sequence analysis of an Andean potato mottle virus middle component RNA cDNA clone: Comparisons of the encoded proteins with those of other comoviruses. Intervirology, 36: 169-180.

5. Lomonossoff GP \& J ohnson JE (1991). The synthesis and structure of comovirus capsids. Progress in Biophysics and Molecular Biology, 55: 107-137.

6. Brioso PST, Pimentel JP, Louro RP, Kitajima EW \& de Oliveira DE (1993). Andean potato mottle virus - Caracterização de uma estirpe infectando naturalmente berinjela (Solanum melanogena). Fitopatologia, 18: 526-532.

7. Achary R, Fry E, Stuart D, Fox G, Rowlands $D \&$ Brown $F$ (1989). The three-dimen- sional structure of foot-and-mouth disease virus at 2.9A resolution. Nature, 337: 709-716.

8. Rossmann MG \& J ohnson JE (1989). Icosahedrical RNA virus structure. Annual Review of Biochemistry, 58: 533-573.

9. Stauffacher $C V$, Usha $R$, Harrington $M$, Schmidt T, Hosur M \& J ohnson J E (1987). The structure of cowpea mosaic virus at 3.5 A resolution. In: Moras D, Drenth J, Strandberg B, Suck D \& Wilson K (Editors), Crystallography in Molecular Biology. Plenum Publishing Corporation, New York, NY, USA, 293-308.

10. Chen Z, Stauffacher $C V$, Schmidt T, Fisher A \& J ohnson J E (1990). In: Brinton MA \& Heinz FX (Editors), New Aspects of Positive-Strand RNA Viruses. American Society for Microbiology, Washington, DC, USA, 218-226.

11. Andrejeva J , Puurand Ü, Merits A, Rabenstein $F$, J ärvekülg $L \&$ Valkonen JPT (1999). Potyvirus helper component-proteinase and coat protein (CP) have coordinated functions in virus-host interactions and the same $\mathrm{CP}$ motif affects virus transmission and accumulation. J oumal of General Virology, 80: 1133-1139.

12. Candelier-Harvey P \& Hull R (1993). Cucumber mosaic virus genome is encapsidated in alfalfa mosaic virus coat protein expressed in transgenic plants. Transgenic Research, 2: 277-285.

13. Briddon RW, Pinner MS, Stanley J \& Markham PG (1990). Geminivirus coat protein gene replacement alters insect specificity. Virology, 177: 85-94.
14. Rojas MR, Zerbini FM, Allison RF, Gilbertson RL \& Lucas WJ (1997). Capsid protein and helper component-proteinase function as potyvirus cell-to-cell movement proteins. Virology, 237: 283-295.

15. de Graaff M, Man in't Veld MR \& J aspars EMJ (1995). In vitro evidence that the coat protein of alfalfa mosaic virus plays a direct role in regulation of plus and minus RNA synthesis: Implications for the life cycle of alfalfa mosaic virus. Virology, 208: 583-589.

16. Bol J F (1999). Alfalfa mosaic virus and ilarviruses: Involvement of coat protein in multiple steps of the replication cycle. J oumal of General Virology, 80: 1089-1102.

17. Sambrook J, Fritsch EF \& Maniatis T (1989). Molecular Cloning: A Laboratory Manual. 2nd edn. Cold Spring Harbor Laboratories, Cold Spring Harbor, NY, USA.

18. Bartel PL, Chien C-T, Sternglanz R \& Fields S (1993). Using the two-hybrid system to detect protein-protein interactions. In: Hartley DA (Editor), Cellular Interactions in Development: A Practical Approach. Oxford University Press, Oxford, UK, 153-179.

19. Gietz D, St J ean A, Woods RA \& Schiestl RH (1992). Improved method for high efficiency transformation of intact yeast cells. Nucleic Acids Research, 20: 1425.

20. Reynolds A \& Lundblad V (1997). Saccharomyces cerevisiae. In: Ausubel FM, Brent R, Kingston RE, Moore DD, Seidman J G, Smith JA \& Struhi K (Editors), Current Protocols in Molecular Biology, Chap. 13. Wiley, New York, NY, USA. 
21. Miller J H (1972). Experiments in Molecular Genetics. Cold Spring Harbor Laboratories, Cold Spring Harbor, NY, USA.

22. Schwede T, Diemand A, Guex N \& Peitsch MC (2000). Protein structure computing in the genomic era. Research in Microbiology, 151: 107-112.

23. Hooft RWW, Vriend G, Sander C \& Abola EE (1996). Errors in protein structures. Nature, 381: 272.

24. Fields S \& Song O (1989). A novel system to detect protein-protein interactions. Nature, 340: 245-246.

25. King AMQ, Lomonossoff GP \& Ryan MD (1991). Picornaviruses and their relatives in the plant kingdom. Seminars in Virology, 2: 11-17.

26. Wellink J, Verver J, van Lent J \& van Kammen A (1996). Capsid proteins of cowpea mosaic virus transiently expressed in protoplasts form virus-like particles. Virology, 224: 352-355.

27. Bertioli DJ, Harris RD, Edwards ML, Coo- per J I \& Hawes WS (1991). Transgenic plants and insect cells expressing the coat protein of arabis mosaic virus produce empty virus-like particles. J ournal of General Virology, 72: 1801-1809.

28. Merits A, Guo D, J ärvekülg I \& Saarma M (1999). Biochemical and genetic evidence for interactions between potato A potyvirus-encoded proteins P1 and P3 and proteins of the putative replication complex. Virology, 263: 15-22.

29. Hong Y, Levay K, Murphy J F, Klein PG, Shaw J G \& Hunt AG (1995). A potyvirus polymerase interacts with the viral coat protein and VPg in yeast cells. Virology, 214: 159-166.

30. Quadt R, Rosdorff HJ M, Hunt TW \& J aspars EMJ (1991). Analysis of protein composition of alfalfa mosaic virus RNAdependent RNA polymerase. Virology, 182: 309-315.

31. Yusibov V \& Loesch-Fries LS (1998). Functional significance of three basic $\mathrm{N}$-termi- nal amino acids of alfalfa mosaic virus coat protein. Virology, 242: 1-5.

32. Horváth GV, Pettkó-Szandtner A, Nikovics K, Bilgin M, Boulton M, Davies J W, Gutiérrez C \& Dudits D (1998). Prediction of functional regions of the maize streak virus replication-associated proteins by protein-protein interaction analysis. Plant Molecular Biology, 38: 699-712.

33. Tenllado F \& Bol J F (2000). Genetic dissection of the multiple functions of alfalfa mosaic virus coat protein in viral RNA replication, encapsidation, and movement. Virology, 268: 29-40.

34. Hartitz MD, Sunter G \& Bisaro DM (1999). The tomato golden mosaic virus transactivator (TrAP) is a single stranded DNA and zinc-binding phosphoprotein with an acidic activation domain. Virology, 263: 1-14.

35. Leuther KK, Salmeron J M \& J ohnson SA (1993). Genetic evidence that an activation domain of GAL4 does not require acidity and may form a ß-sheet. Cell, 72: 575-585. 